\title{
Coherent kimberlite at EKATI, Northwest Territories, Canada: textural and geochemical variations and implications for emplacement
}

\author{
K. Webb ${ }^{1}$, B. Crawford ${ }^{2}$, T. Nowicki ${ }^{1}$, C. Hetman ${ }^{1}$ and J. Carlson ${ }^{2}$ \\ ${ }^{1}$ Mineral Services Canada Inc., Canada, ${ }^{2}$ BHP Billiton Diamonds Inc., Canada \\ (kimberley.webb@mineralservices.com / Fax: +1 6049806751 / Phone: +1 6049806771 )
}

\section{Introduction}

The term 'coherent' is used in a general non-genetic sense to describe kimberlite characterised by a crystalline groundmass and lacking readily discernable evidence of fragmentation. Coherent kimberlite has been encountered in three main geological settings worldwide: sheet intrusions (dykes and sills), root zone intrusions (irregular pipes) and high-level pipe fills (steep-sided pipes). The EKATI property in the Northwest Territories of Canada (Fig. 1) provides a unique opportunity to study coherent kimberlite from a range of emplacement settings. The majority of EKATI kimberlites are small pipe-like bodies filled dominantly by volcaniclastic kimberlite (VK), including mainly resedimented and lesser primary deposits, as described by Nowicki et al. $(2004,2008)$. Coherent kimberlite (CK) occurs as minor sheet intrusions, classified as hypabyssal kimberlite (HK), and as volumetrically significant high-level pipe fills, termed pipe-fill CK (pfCK). A recent study of the geochemical trends in a variety of volcaniclastic and coherent EKATI kimberlites (Nowicki et al., 2008) provides insight on the formation of these diverse bodies. Variations in bulk composition of selected kimberlites were found to correlate with the emplacement settings and textural character of analysed samples. In this contribution, we confirm, expand and build on this work.

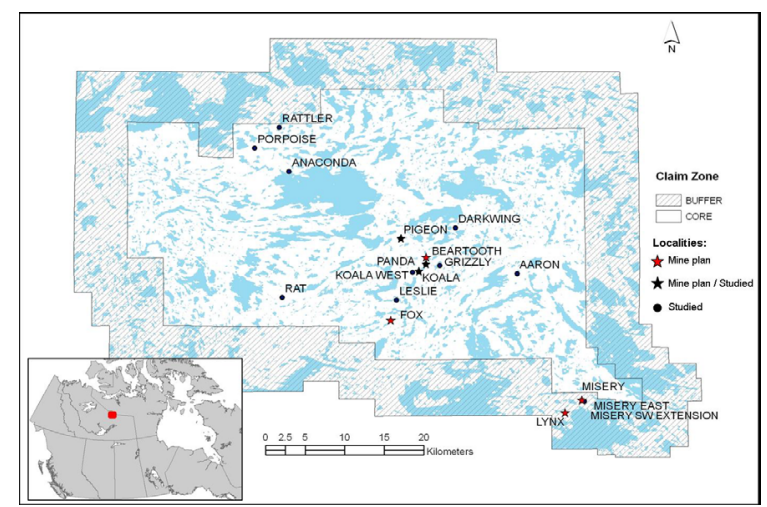

Figure 1: Location of EKATI kimberlites studied.

\section{Scope and objectives of study}

While Nowicki et al. (2008) analysed CK samples from a variety of emplacement settings, the results were grouped and interpreted in terms of the two endmember types (HK and pfCK). This study investigates a larger set of CK samples from fourteen localities representing six contrasting geological settings (Table 1). The settings are interpreted based on drill core intersections, in some cases supported by geophysics and mining excavations. The petrographic and geochemical characteristics of these samples are examined in detail in relation to their geological setting and are compared to five previously analysed samples of primary volcaniclastic kimberlite (PVK) from the Koala and Panda kimberlites.

Table 1: Kimberlites investigated in this study categorised by CK type and geological setting.

\begin{tabular}{|c|l|c|}
\hline $\begin{array}{c}\text { CK } \\
\text { type }\end{array}$ & \multicolumn{1}{|c|}{ Apparent Setting } & Kimberlite \\
\hline \multirow{4}{*}{ HK } & $\begin{array}{l}\text { A) minor intrusion in host rock, } \\
\text { isolated from pipes }\end{array}$ & $\begin{array}{c}\text { Anaconda } \\
\text { Porpoise }\end{array}$ \\
\cline { 2 - 3 } & $\begin{array}{l}\text { B) minor intrusion in host rock, } \\
\text { peripheral to pipe }\end{array}$ & $\begin{array}{c}\text { Koala W } \\
\text { Misery SW }\end{array}$ \\
\cline { 2 - 3 } & $\begin{array}{l}\text { C) minor phase within VK pipe fill } \\
\text { - probable sheet intrusions }\end{array}$ & $\begin{array}{c}\text { Rat } \\
\text { Rattler } \\
\text { Pigeon-S }\end{array}$ \\
\hline \multirow{4}{*}{ pfCK } & $\begin{array}{l}\text { A) large volume pipe fill CK, } \\
\text { no associated VK }\end{array}$ & $\begin{array}{c}\text { Leslie } \\
\text { Grizzly }\end{array}$ \\
\cline { 2 - 3 } & $\begin{array}{l}\text { B) large volume pipe fill CK, } \\
\text { associated with VK }\end{array}$ & $\begin{array}{c}\text { Darkwing } \\
\text { Pigeon }\end{array}$ \\
\cline { 2 - 3 } & $\begin{array}{l}\text { C) smaller bodies of CK within } \\
\text { or associated with VK-filled pipes }\end{array}$ & $\begin{array}{c}\text { Aaron } \\
\text { Panda } \\
\text { Misery E }\end{array}$ \\
\hline
\end{tabular}

The primary objectives of this work are to: (i) establish the extent, if any, to which the sheet intrusions within host rocks and within VK pipe fills differ from each other; (ii) determine the range and type of textural and component characteristics that can be considered diagnostic of specific emplacement settings; (iii) assess whether variations in geochemical composition of the samples can be shown to correspond with the spectrum of petrographic characteristics observed; and (iv) elucidate possible emplacement processes involved in the formation of pipe-fill coherent kimberlite at EKATI and the relationship of these to volcaniclastic processes. The study focuses in particular on petrographic and geochemical evidence indicative of varying degrees of fragmentation of the kimberlite magma, as well as the extent to which this has interacted with volcaniclastic material. 
Table 2: Summary of key petrographic features of samples investigated in this study. Type - geological emplacement category (Table 1); Samples - number of petrography and geochemistry (in brackets) samples investigated; OLV\% percentage total olivine; Broken OLVm - percentage of broken olivine macrocrysts; $\mathrm{MC}-$ magmaclasts $(\mathrm{pseudo}=$ pseudo-magmaclasts); CRX = country rock xenoliths; VK autoliths - clasts of previous VK within CK; Mineralogy groundmass minerals $($ mont $=$ monticellite; $\mathrm{spi}=$ spinel; $\mathrm{phl}=$ phlogopite car $=$ carbonate) Pigeon-S $=$ south crater.

\begin{tabular}{|c|c|c|c|c|c|c|c|c|c|c|}
\hline Type & Kimberlite & Drill Hole & Samples & OLV \% & $\begin{array}{l}\text { Broken } \\
\text { OLVm }\end{array}$ & $\mathrm{MC}$ & CRX \% & CRX lith & VK autoliths & Mineralogy \\
\hline \multirow{2}{*}{ HK-A } & Anaconda & 96-17 & 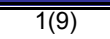 & 50 & $><2$ & absent & $2-10$ & CRG, CRM & absent & mont spi \\
\hline & Porpoise & $94-11$ & $2(6)$ & $45-50$ & 0 & absent & $3-25$ & CRG, CRM & absent & phl spi mont \\
\hline \multirow{2}{*}{ HK-B } & Koala W & KWDC-01 & $2(4)$ & $40-45$ & $<2$ & absent & $2-10$ & CRG, CRM, MST & present & phl mont spi \\
\hline & Misery SW & MDC-01 & $1(5)$ & 50 & $3-5$ & absent & $7-10$ & CRG & absent & spi mont \\
\hline \multirow{3}{*}{ HK-C } & Rat & $94-08$ & $4(7)$ & $45-50$ & 2 & pseudo & $<1-3$ & CRM & common & spi \\
\hline & Rattler & $96-13$ & $3(6)$ & $45-50$ & $1-3$ & local pseudo & $1-3$ & CRG & rare-absent & spi \\
\hline & Pigeon-S & $97-54$ & $0(2)$ & & & & & & & \\
\hline \multirow{2}{*}{ pfCK-A } & Leslie & LDC-03\&09 & "6(8) & $245-55$ & $5-10$ & local pseudo & $2-10$ & CRG, CRM & absent & phl spi mont \\
\hline & Grizzly & 92-02 & $2(6)$ & $50-60$ & $7-10$ & local pseudo & $2-5$ & CRG, CRM & absent & spi mont \\
\hline \multirow{2}{*}{ pfCK-B } & Darkwing & $07-06$ & $5(4)$ & $45-50$ & $1-5$ & absent-poss & $<1-10$ & CRG & abs.-common & spi mont \\
\hline & Pigeon & $97-55$ & $2(4)$ & $35-40$ & 15 & probable & $1-5$ & CRG, CRM, MST & rare & spi per mont \\
\hline \multirow{3}{*}{ pfCK-C } & Aaron & $97-57$ & $2(4)$ & $50-60$ & 5 & local & $1-3$ & CRG, CRM & absent & spi mont \\
\hline & Panda & PUC3-1 & $1(1)$ & $50-55$ & $2-3$ & local pseudo & 7 & CRG, CRM \& MST & present & spi car \\
\hline & Misery $\mathrm{E}$ & $93-13$ & $2(7)$ & 50 & 2 & local pseudo & $2-5$ & $\mathrm{CRG}$ & absent & spi phl mont \\
\hline
\end{tabular}

\section{Petrography}

Petrographic results are summarised in Table 2 and key features are illustrated in Fig. 1. No systematic difference in olivine content is observed between the different CK types but, in general, broken olivine macrocrysts are rare or absent in samples interpreted as HK whereas most of the pfCK samples show a significant proportion of broken grains. Exceptions include the sample from Misery SW (interpreted in drill core to be an HK sheet peripheral to a CK-filled volcanic pipe) and some of the Darkwing samples.

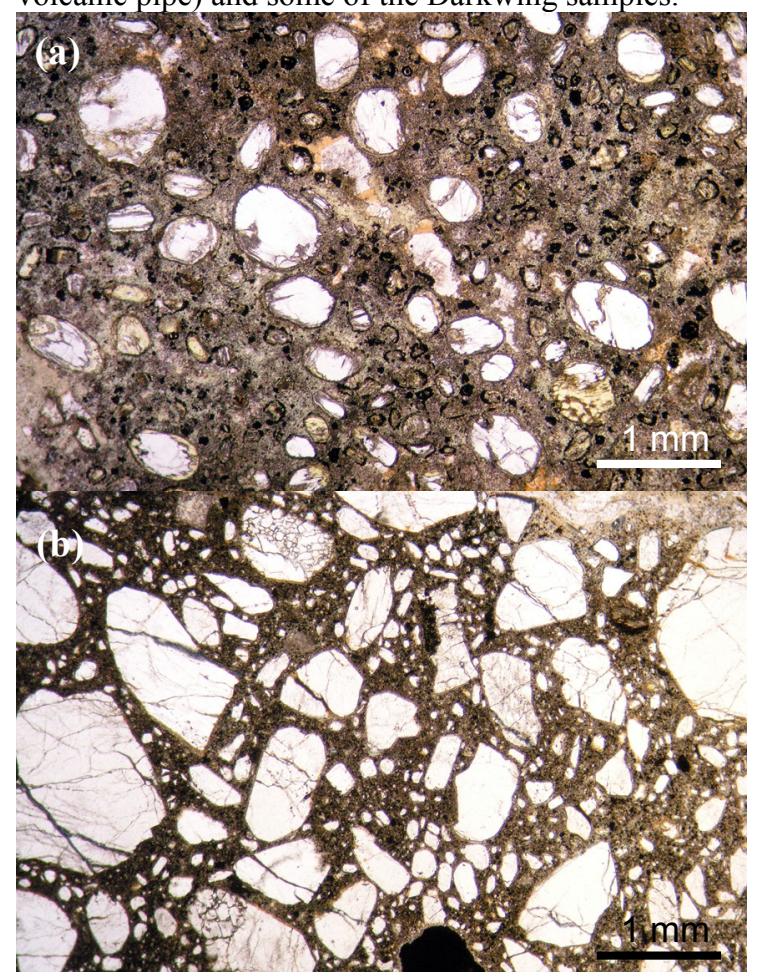

Figure 1: Photomicrographs of (a) Porpoise HK and (b) Grizzly pfCK showing the contrasting abundance of broken olivine macrocrysts, and heterogeneous olivine distribution in the sample from Grizzly.
No magmaclasts were observed in the HK samples, but pseudo-magmaclastic textures (resulting from the inhomogeneous replacement of primary groundmass by serpentine and/or carbonate) are evident in HK bodies emplaced into VK-filled pipes. Localised pseudomagmaclastic textures are common in most of the pfCK samples and possible true magmaclasts are evident in the samples from Pigeon and Darkwing. Interestingly, Darkwing also includes intervals with no evidence of magmaclasts which, combined with low broken olivine abundance, indicates typical HK-like textures. Country rock xenolith content is variable but typically low to very low and no consistent differences in this regard exist between the different types of CK. As would be expected, a high proportion of the CK bodies that are associated with VK contain autoliths of this material. Mineral assemblages observed in the crystalline groundmass of the samples include (in varying relative proportions) monticellite-spinel, spinel phlogopite-monticellite, spinel-carbonate, and spinelperovskite-monticellite. No systematic mineralogical differences are evident between different CK types.

\section{Geochemistry}

The dataset presented in Nowicki et al. (2008) has been expanded here by analysing a further twenty samples for major and trace elements (using a combination of ICP-AES and ICP-MS analysis of lithium metaborate fusion disks). Eight of the total 73 analyses were excluded from the interpretation due to clear evidence for significant contamination by crustal material.

The augmented geochemical results emphatically support the fundamental compositional distinction between the majority of rocks interpreted to be $\mathrm{HK}$ and those interpreted to be pipe-filling CK. Specifically, pfCK samples mostly show lower concentrations of $\mathrm{TiO}_{2}$, other incompatible elements (e.g. La, Nb), $\mathrm{V}$ and $\mathrm{CaO}$, and higher concentrations of $\mathrm{SiO}_{2}, \mathrm{MgO}$ and $\mathrm{Ni}$ (e.g. Fig. 2). Misery SW is the only HK locality that does not conform to this relationship: it shows a 
compositional range which coincides with that of the pfCK samples and that is similar to the compositions of the Misery E pfCK. This suggests, in combination with higher broken olivine macrocryst abundance than other HK samples, that the drill core intersection may have been misinterpreted and instead forms part of the adjacent CK-filled pipe.

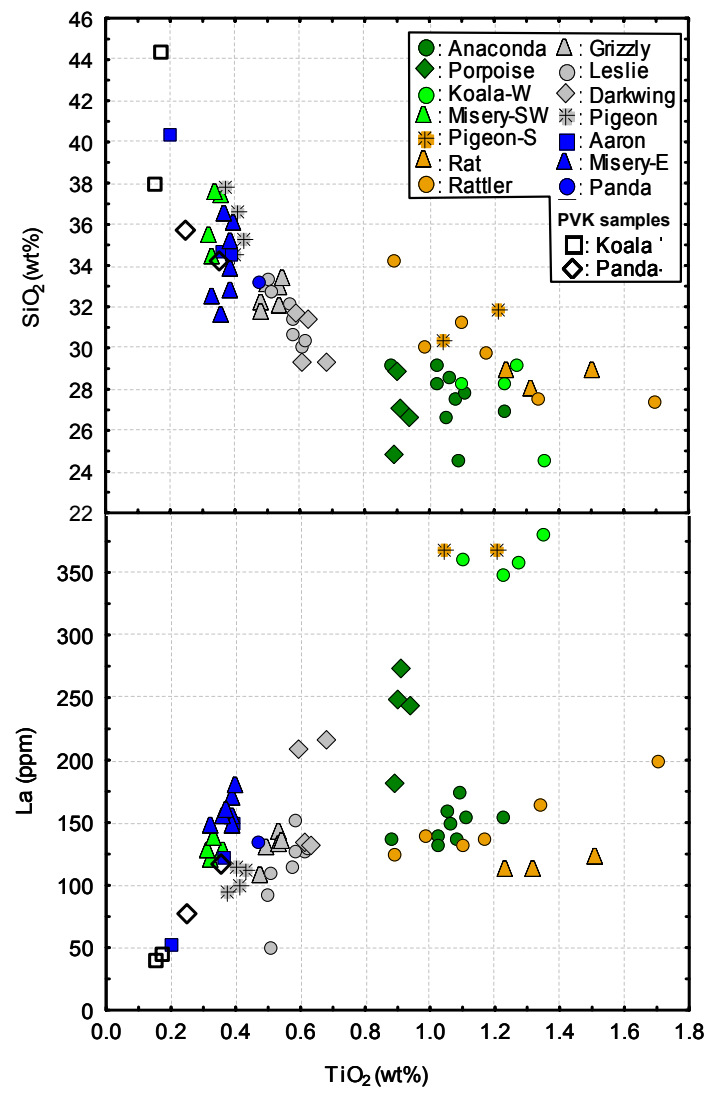

Figure 2: Bivariate compositional plots illustrating variations in $\mathrm{TiO}_{2}, \mathrm{SiO}_{2}$ and $\mathrm{La}$ by locality (colour coded by CK type; see Table 1 ).

Geochemical variations are evident within each of the two main categories of CK. Samples of HK define broadly cohesive, partially overlapping compositional fields for each locality, reflecting distinct geochemical differences between the source magmas. Significantly, there are no consistent trends or correlations between or within the HK compositional fields. In contrast, the pfCK samples appear to define broad linear trends with respect to several elements (e.g. Fig 2), indicating that similar processes are controlling much of the compositional variation. The specific type of pfCK appears to be broadly reflected in the observed compositional trends. In particular, samples from the two large volume pfCK localities (Leslie and Grizzly), as well as from Darkwing, plot closer to the HK end of the pfCK compositional range, whereas the smaller pfCK bodies and those with a clearer volcaniclastic association (e.g. Pigeon) tend towards compositions observed in primary volcaniclastic kimberlite (PVK).

\section{Discussion}

The preliminary findings of this study are as follows: i) Subtle geochemical differences are evident between HK intruding host rock and that emplaced into VKfilled pipes. These are accompanied by petrographic evidence in the latter for interaction with $\mathrm{VK}$ and, possibly, alteration effects associated with volcanic degassing; ii) The main petrographic difference between samples of $\mathrm{HK}$ and $\mathrm{pfCK}$ is a higher abundance of broken olivine in the latter. In some cases this is accompanied by heterogeneous textures (such as non-uniform olivine distribution) suggestive of magma fragmentation. The degree of olivine breakage within pfCK varies between localities and may reflect varying degrees of fragmentation; iii) Petrographic variations correlate with compositional differences between HK and pfCK that suggest a depletion of groundmass constituents in the latter. Furthermore, within the larger volume pfCK types (Table 1) there appears to be a rough correlation between degree of olivine breakage and deviation from HK compositions; iv) The generally higher broken olivine abundance in pfCK relative to HK suggests more turbulent and possibly explosive emplacement processes, supported by the observed geochemical evidence for fines loss. The generally parallel compositional trends observed for pfCK localities suggests control by similar processes and cannot be explained by contamination. The fact that these trends roughly parallel the overall HK-pfCKPVK array supports the contention that volcanic eruption accompanied by varying degrees of fines loss and olivine breakage is responsible for much of the compositional and textural variations in EKATI pfCK.

\section{Conclusions}

The results of this study demonstrate that an assessment of the geological context, petrographic textural and component characteristics, and the geochemical composition of a particular kimberlite occurrence can be combined and applied to confirm the setting and constrain the processes involved in emplacement. This has economic significance for exploration, evaluation and to a lesser extent mining (predicting and delineating the extent, external morphology and internal geology of a body, and interpretation of potential controls on diamond distribution). Further research is planned to investigate the degree to which the textural and geochemical relationships established for $\mathrm{CK}$ at EKATI apply to other kimberlite fields, and whether this approach can help to constrain processes involved in the formation of $\mathrm{CK}$ in root zone intrusions.

\section{References}

Nowicki, T., Crawford, B., Dyke, D., Carlson, J. McElroy, R., Oshust, P. and Helmsteadt, H., 2004. The geology of kimberlite pipes of the Ekati property, Northwest Territories, Canada. Lithos, 76(1-4):1-27.

Nowicki, T. Porritt, L., Crawford, B. and Kjarsgaard, B., 2008. Geochemical trends in kimberlites of the Ekati property, Northwest Territories, Canada: insights on volcanic and resedimentation processes. In press. 